\title{
Copropiedad como estrategia fiscal para atenuar la carga tributaria en México
}

\section{Co-ownership as a fiscal strategy to mitigate the tax burden in Mexico}

\author{
HERNÁNDEZ-SANDOVAL, Rosa Hilda*†, GAONA-TAMEZ, Laura Leticia, AGUILERA- \\ MANCILLA, Gabriel y TORRES-HERNANDEZ, Eric Arturo
}

Universidad Autónoma de Coahuila, Blvd. V Carranza S/N Col. Republica, CP25280, Saltillo, Coah., México

ID $1^{\text {er }}$ Autor: Rosa Hilda, Hernández-Sandoval / ORC ID: 0000-0002-0563-5705, Researcher ID Thomson: X-39652018, CVU CONACYT ID: 640368

ID $1^{\mathrm{er}}$ Coautor: Laura Leticia, Gaona-Tamez / ORC ID: 0000-0002-8411-830X, Researcher ID Thomson: T-9572-2018, CVU CONACYT ID: 260350

ID $2^{\text {do }}$ Coautor: Gabriel, Aguilera-Mancilla / ORC ID: 0000-0002-0128-9155, Researcher ID Thomson: 2950-2018, CVU CONACYT ID: 510469

ID $3^{\text {er }}$ Coautor: Eric Arturo, Torres-Hernandez / ORC ID: 0000-0002-3264-2986, Researcher ID Thomson: X-79212018, CVU CONACYT ID: 953736

DOI: $10.35429 /$ JLA.2019.9.3.12.22

Recibido 01 de Julio, 2019; Aceptado 25 de Septiembre, 2019

\begin{abstract}
Resumen
El objetivo de este investigación es describir las obligaciones y procedimientos fiscales del artículo $92 \mathrm{del}$ impuesto sobre la renta para presentar caso práctico en copropiedad. Entendiéndose por este ultimo la propiedad de una cosa compartida con otro u otros, el procedimiento metodológico se realizará cuando una Persona Física renta a Persona Moral un bien inmueble, el ingreso que percibe la persona física en forma mensual y este a la vez lo distribuye a sus copropietarios de acuerdo al porcentaje que se asignó en el contrato de arrendamiento del bien inmueble. Como procesar un caso práctico en copropiedad?. Este régimen se aprovecha poco por desconocimiento de los contribuyentes debido a la escasa información que establece la ley. Esta investigación se presentará con enfoque jurídico y fiscal, de acuerdo al Articulo 5 Constitucional, a ninguna persona podrá impedirse que se dedique a la profesión, industria, comercio o trabajo que le acomode siendo lícitos. En el estudio de casos en copropiedad se observaran los beneficios de la estrategia fiscal en la disminución de ISR al distribuirse los ingresos entre los copropietarios y las deducciones autorizadas que pueden optar por deducir los copropietario en la declaración anual, seguido con el conyugue.
\end{abstract}

Copropiedad, Estrategia fiscal, Beneficios

\begin{abstract}
The objective of this investigation is to describe the obligations and fiscal procedures of Article 92 of the income tax to present a case in co-ownership. Being understood as Co-ownership, the ownership of a thing shared with another or others. The methodological procedure will be carried out when an individual rents a real estate property to a legal entity or company, the income received by the individual on a monthly basis and the latter distributes it to their co-owners according to the percentage assigned in the lease agreement of the real property.How to process a case study in co-ownership?. This regime is little used due to taxpayers ignorance because the scarce information established by law. This investigation will be presented with a legal and fiscal focus, according to Article 5 of the Constitution: no person can be prevented from engaging in the profession, industry, commerce or work that suits him or she while being lawful. In the case study in co-ownership the benefits of the fiscal strategy resulted in the decrease of ISR when distributing the income among the co-owners and the authorized deductions that the co-owners can choose to deduct in the annual return, followed by the spouse.
\end{abstract}

Co-ownership, Tax Strategy, Benefits

Citación: HERNÁNDEZ-SANDOVAL, Rosa Hilda, GAONA-TAMEZ, Laura Leticia, AGUILERA-MANCILLA, Gabriel y TORRES-HERNANDEZ, Eric Arturo. Copropiedad como estrategia fiscal para atenuar la carga tributaria en México. Revista de Aplicaciones del Derecho. 2019. 3-9: 12-22.

\footnotetext{
*Correspondencia al Autor (Correo Electrónico: josez_orozco@ hotmail.com)

$\dagger$ Investigador contribuyendo como primer autor.
} 


\section{Introducción}

El objetivo de esta investigación es describir las obligaciones y los procedimientos fiscales para que el contribuyente aplique los beneficios que puede obtener al utilizar el régimen de copropiedad, para esto se presentara una caso práctico sustentado en el artículo 92 de la ley de impuesto sobre la renta, basado en el artículo 5 Constitucional: que en parte establece que el contribuyente puede planear una actividad como estratega siempre y cuando sea lícito, este régimen ayudará a disminuir la base gravable al aplicar la distribución de los ingresos de acuerdo a los porcentajes que corresponda a cada uno de los copropietarios. Si los contribuyentes conocen el régimen de copropiedad podrán hacer uso al aplicar procedimientos fiscales legales $y$ constitucionales, con esta investigacion y con el caso práctico: podrán los contribuyentes aplicar la estrategia en copropiedad?.

Copropiedad. Condominio de una cosa. Hay copropiedad cuando una cosa o derecho pertenece pro-individuo a varias personas, así en derecho mexicano, se adoptó la teoría clásica en donde se explica esta figura jurídica, no como el dominio de cada copropietario sobre determinadas partes de la cosa o derecho, sino un derecho de propiedad sobre el todo en cierta proporción a la que se le da el nombre de parte alícuota. Sin embargo esta teoría fue influida por la concepción alemana, al reglamentar la formación de una colectividad para ciertos efectos, sin llegar a reconocer a la copropiedad una personalidad jurídica (Jurídico, 1999).

Cuando los ingresos de las personas físicas deriven de bienes en copropiedad, deberá designarse a uno de los copropietarios como representante común, el cual deberá llevar los libros, expedir los comprobantes fiscales y recabar la documentación que determinen las disposiciones fiscales, así como cumplir con las obligaciones en materia de retención de impuestos a que se refiere esta Ley (Calvo \& Montes, 2019).

\section{Justificación}

Esta investigación beneficiará a los contribuyentes personas físicas que cuenten con un bien en la que podrán planificar la copropiedad como estrategia fiscal y obtener beneficios fiscales.
Así mismo aportará conocimiento a los contribuyentes que reúnan las características de este régimen. Esta investigación resolverá problemas específicos a un grupo de contribuyentes para la toma de decisiones en copropiedad. Se presenta caso práctico para que los contribuyentes puedan realizar procedimientos fiscales y legales en el cual podrán adquirir conocimientos para su aplicación inmediata. Cuenta con soporte fiscal, legal así como Constitucional.

\section{Problema}

La copropiedad es un régimen que está fundamentado en la ley del impuesto sobre la renta en su artículo 92, pero pocos contribuyentes hacen uso de esta figura porque existe escasa o poca información sobre los procedimientos, para aplicar esta figura del régimen de copropiedad se requiere que el contribuyente conozca la base constitucional, legal y fiscal para su aplicación como lo establece la ley fiscal.

\section{Hipótesis}

H1. Si el contribuyente conoce los procedimientos y requisitos para llevar a cabo el régimen de copropiedad podrá obtener beneficios fiscales así como disminución de cargas administrativas.

Ho. $\mathrm{Si}$ el contribuyente persona física desconoce los procedimientos fiscales y administrativos no estará en condiciones de obtener beneficios fiscales y administrativos.

\section{Objetivos}

Se presenta objetivo general y dos objetivos específicos para determinar la línea a seguir.

\section{Objetivo General}

Identificar los procedimientos fiscales y responsabilidades que debe tener el contribuyente responsable para hacer uso del régimen de copropiedad con enfoque fiscal.

\section{Objetivos específicos}

- Identificar los procedimientos fiscales para hacer uso de la figura de copropiedad con un caso práctico. 
- Analizar las responsabilidades fiscales que tiene el representante legal al aplicar el régimen de copropiedad.

\section{Marco Teórico}

Antecedentes

\section{Constitución Política de los Estados Unidos Mexicanos.}

A ninguna persona podrá impedirse que se dedique a la profesión industria, comercio o trabajo que le acomode, siendo lícitos. El ejercicio de esta libertad solo podrá vedarse por determinación judicial, cuando se ataquen los derechos de terceros, o por resolución gubernativa, dictada en los términos que marque la Ley, cuando se ofendan los derechos de la sociedad. Nadie puede ser privado del producto de su trabajo, sino por resolución judicial (CPEUM, 2019).

Un profesionista o un contribuyente que desee planear una actividad lo puede hacer siempre que esta sea lícita, en este caso se pretende realizar una actividad en copropiedad en la cual se pueden obtener beneficios fiscales.

\section{Código Civil.}

En el artículo 938 de código civil establece: hay copropiedad cuando una cosa o un derecho pertenecen pro-indiviso a varias personas, asimismo el 945: ninguno de los condueños podrá, sin el consentimiento de los demás, hacer alteraciones en la cosa común, aunque de ellas pudiera resultar ventajas para todos, el 947: para que haya mayoría se necesita la mayoría de copropietarios y la mayoría de intereses y por ultimo 948: si no hubiere mayoría, el juez oyendo a los interesados resolverá lo que debe hacerse dentro de lo propuesto por lo mismo (CCDF, 2019).

De acuerdo a los artículos citados para tomar decisiones se requiere que la mayoría esté de acuerdo para tomar decisiones en su aspecto legal.

Ley de Impuesto sobre la Renta
De acuerdo al artículo 92 de la ley de ISR, cuando los ingresos de las personas físicas deriven de bienes en copropiedad, deberá designarse a uno de los copropietarios como representante común, el cual deberá llevar los libros, expedir los comprobantes fiscales y recabar la documentación que determinen las disposiciones fiscales, así como cumplir con las obligaciones en materia de retención de impuestos a que se refiere esta Ley (Calvo \& Montes, 2019).

Cuando se realicen actividades empresariales a través de una copropiedad, el representante común designado determinará, en los términos de esta Sección, la utilidad fiscal o la pérdida fiscal, de dichas actividades $\mathrm{y}$ cumplirá por cuenta de la totalidad de los copropietarios las obligaciones señaladas en esta Ley, incluso la de efectuar pagos provisionales. Para los efectos del impuesto del ejercicio, los copropietarios considerarán la utilidad fiscal o la pérdida fiscal que se determine conforme al artículo 109 de esta Ley, en la parte proporcional que de la misma les corresponda y acreditarán, en esa misma proporción, el monto de los pagos provisionales efectuados por dicho representante (Calvo \& Montes, 2019).

Responsabilidad solidaria.

Los copropietarios responderán solidariamente por el incumplimiento del representante común de acuerdo al artículo 92 LISR (Calvo \& Montes, 2019).

Son responsables solidarios con los contribuyentes, los retenedores y las personas a quienes las leyes impongan la obligación de recaudar contribuciones a cargo de los contribuyentes, hasta por el monto de dichas contribuciones.

De acuerdo al art. 92 (CFF, 2019). Las personas que estén obligadas a efectuar pagos provisionales por cuenta del contribuyentes, hasta por el monto de dichos pagos y que no incurra en los siguientes supuestos:

a). No solicitar la inscripción del R.F.C.

b). Cambie de domicilio sin presentar aviso.

c). No llevar contabilidad o la oculte o la destruya. 
d). Desocupe el local donde tenga el domicilio fiscal.

Asimismo, tendrán la obligación de:

VIII. Quienes manifiesten la voluntad de asumir responsabilidad solidaria.

Sociedad conyugal.

Esto es aplicable a los integrantes de la sociedad conyugal de acuerdo al Art. 92 LISR (Calvo \& Montes, 2019).

De acuerdo al RISR Artículo142. Cuando se trate de los integrantes de una sociedad conyugal, podrán optar que aquel que obtengan mayores ingresos, acumule la totalidad de los ingresos obtenidos por bienes o inversiones en los que ambos sean propietarios o titulares, pudiendo efectuar las deducciones correspondientes a dichos bienes o inversiones (Calvo \& Montes, 2019).

Para los efectos del artículo 92 LISR tratándose de ingresos que deriven de otorgar el uso o goce temporal o de la enajenación de bienes, cuando dichos bienes están en copropiedad o pertenezcan a los integrantes de una sociedad conyugal, deberán presentar sus declaraciones de pagos provisionales y del ejercicio, tanto el representante común como los representados y los integrantes de la sociedad conyugal, por la parte proporcional de ingresos que les correspondan a cada uno, excepto cuando opten por aplicar lo dispuesto en los artículo 142 y145 del reglamento (Calvo $\&$ Montes, 2019).

Para efectos del párrafo anterior, cada contribuyente podrá deducir la parte proporcional de las deducciones relativas al periodo por el que se presente la declaración.

En esta rubro el copropietario al declarar la parte proporcional de los ingresos podrá optar por deducir la deducción opcional del $35 \%$, así como las deducciones personales y por consiguiente las deducciones por decreto que corresponde a la educación de acuerdo a la tabla No. 14: que establece limitante de la educación.

\section{Ley del Impuesto al valor agregado.}

Según se observa, en el caso de copropiedad, se indica que los contribuyentes que tengan en copropiedad una negociación designarán representante común previo aviso de tal designación ante las autoridades tributarias, y será él quien a nombre de los copropietarios cumpla con las obligaciones establecidas en la Ley del IVA (LIVA, 2019). Entre otras, presentar la declaración informativa de las operaciones realizadas con terceros por cuenta de todos los copropietarios.

En este sentido, algunos contribuyentes consideraron que la disposición citada no era aplicable a los copropietarios que obtienen ingresos por el arrendamiento de inmuebles en copropiedad, pues sólo se refiere a una negociación y, por tanto, sólo aplica a quienes perciben ingresos por actividades empresariales por bienes en copropiedad.

Al efecto, la Tercera Sala Regional Metropolitana del TFJFA emitió una tesis aislada en la que señala que cuando los copropietarios de un inmueble otorgan el uso y goce temporal del bien mediante contrato de arrendamiento a un tercero, considerando que el arrendamiento constituye una negociación, precisamente porque el arrendador obtiene ingresos por ello, es manifiesto que la hoy actora en su calidad de representante común de la negociación arrendamiento del inmueble, debe cumplir con las obligaciones establecidas en la Ley del IVA a nombre de los copropietarios (TFJFA, 2019).

Opción de deducción opcional.

De acuerdo al Artículo 196 RISR. Los contribuyentes que opten por efectuar la deducción a que se refiere el articulo 115, párrafo II de la ley, lo deberán hacer por todos los inmuebles por los que otorguen el uso o goce temporal, incluso por aquellos en los que tenga el carácter de copropietarios, a mas tardar en la fecha en el que se presente la primera declaración provisional que corresponda al año de calendario que se trate, y una vez ejercida no podrá variarse en los pagos provisionales de dicho año, pudiendo cambiarse la opción al presentar la declaración anual del ejercicio a que correspondan (RISR, 2019). 
Los contribuyentes que otorguen el uso o goce temporal de bienes inmuebles podrán optar por deducir el $35 \%$ de los ingresos a que refiere este capítulo según tabla No. 15, en sustitución de las deducciones a que este artículo se refiere. Quienes ejercen este opción podrán deducir además, el monto de las erogaciones por concepto del impuesto predial de dichos inmuebles correspondientes al año de calendario o al período durante el cual se obtuvieron los ingresos en el ejercicio según corresponda de acuerdo al Artículo 115 LISR (LISR, 2019).

\section{Aspecto jurídico.}

La doctrina tradicional, de inspiración romana, considera la copropiedad como una forma de propiedad individual. Cada copropietario es dueño de una cuota, parte ideal, sobre la cual ejerce su dominio exclusivo. Se puede incluso disponer de ella, gravarla, reivindicarla. Sobre la cosa misma materialmente considerada, cada copropietario no puede obrar sin el consentimiento de los demás (Zúñiga, 2013).

Los copropietarios tienen derecho para obligar a otros copropietarios a contribuir a los gastos de conservación del objeto común estando únicamente eximido de esta obligación quien renuncie a la parte que le pertenece en el dominio. Se trata de los gastos necesarios para la conservación de la cosa común, no de aquellos suntuarios o de puro lujo. La renuncia de la cuota implica que se incrementen las cuotas de los demás en proporción a la cuota que tenían.

Ninguno de los dueños esta facultado, sin consentimiento de los demás para hacer alteraciones en la cosa común aunque de ellas pudieran resultar ventajas para todos.

Ningún copropietario esta obligado a permanecer en el régimen de copropiedad. Existe por tanto el derecho de cada uno de los de los copropietarios a solicitar la división de la cosa común.

Copropietarios gozan de plena facultad de disposición jurídica de cuota sea a título gratuito u oneroso, y una limitada facultad de disposición material pues deben contar con la autorización de todos los copropietarios.
En cuanto a la administración de los bienes comunes, todos los copropietarios tienen derecho a administrar la cosa común en forma igualitaria y así percibir los frutos que esta propiedad produzca. Esta administración se podrá realizar a través de acuerdos fijados en estatutos internos que rijan la copropiedad (Cuadros, 1995).

\section{Resolución miscelánea Fiscal.}

Fechas en que debe presentar el representante común los pagos previsionales y definitivos: los pagos provisionales $\mathrm{y}$ definitivos generalmente deben presentarse cada mes, a mas tardar el día 17 del mes siguiente al que corresponda el pago: sin embargo tiene de uno a cinco días mas de plazo según el sexto digito numérico de su Registro Federal de Causante (www.2.sat.gob.mxsitio, 2012).

\begin{tabular}{|l|l|}
\hline \multicolumn{1}{|c|}{ Sexto digito RFC } & \multicolumn{1}{c|}{ Fecha límite de pago } \\
\hline $1 \mathrm{y} 2$ & Día 17 más un día hábil \\
\hline $3 \mathrm{y} 4$ & Día 17 más dos hábil \\
\hline $5 \mathrm{y} 6$ & Día 17 más tres hábil \\
\hline $7 \mathrm{y} 8$ & Día 17 más cuatro hábil \\
\hline $9 \mathrm{y} 0$ & Día 17 más cinco día hábil \\
\hline
\end{tabular}

Tabla 1 En esta tabla se presenta como opción los días que puede pagar el impuesto el contribuyente o representante común lo cual es: de uno a cinco días de mas que ofrece Resolución Miscelánea Fiscal

\section{Metodología de Investigación}

Se presenta procedimiento con un caso práctico de copropiedad en el aspecto, fiscal. Al comparar el cálculo de una persona física como si recibiera el total del ingreso en copropiedad tabla No. 12: y el resultado de impuesto de los integrantes de la copropiedad para observar el efecto o el beneficios de aplicar la copropiedad de acuerdo a tabla No. 13.

Asimismo, se presenta la base constitucional para fundamentar que la estrategia es lícita, la ley del impuesto sobre la renta, ley del impuesto al valor agregado, Código Civil entre otras, la cual los contribuyentes pueden hacer uso del régimen en copropiedad. 


\section{Tipo de Investigación}

Esta investigación es de tipo descriptivo, se identifica las características especificas de los copropietarios y del representante legal que perciben ingresos en el régimen de copropiedad. Se aplica un enfoque cualitativo porque se utilizó información documental: leyes Fiscales, legales, Constitucionales, Resolución Miscelánea, y del impuesto al valor agregado para sustentar lo que se pretende defender.

\section{Resultados}

En este apartado de resultados se podra observar los beneficios que puede obtener el contribuyente con los procedimientos, cálculos, comparacion y sustento del caso práctico: Persona fisica renta un bien inmueble a una Persona Moral en copropiedad de acuerdo a la proporcion, y representado por un representante común, de acuerdo a la tabla No. 2: que corresponde a seis copropietarios los cuales perciben mensualmente un total de: $\$$ $242,590.00$, los copropietarios en sus porcientos respectivos, siendo el copropietarios No. 2, el representante común del contrato legal de la copropiedad. asimismo se presentan 15 tablas para demostrar los procedimientos así como los beneficios.

\begin{tabular}{|l|r|r|}
\hline \multicolumn{1}{|c|}{ Concepto } & \multicolumn{1}{c|}{ Valor } & \multicolumn{1}{c|}{$\%$} \\
\hline Copropietario 1 & $16,132$. & 6.65 \\
\hline Copropietario 2 & $107,710$. & 44.40 \\
\hline Copropietario 3 & $40,391$. & 16.65 \\
\hline Copropietario 4 & 46,092 & 19.00 \\
\hline Copropietario 5 & 16,132 & 6.65 \\
\hline Copropietario 6 & $16,132$. & 6.65 \\
\hline Total & $\$ 242,590$ & 100.00 \\
\hline
\end{tabular}

Tabla 2 En esta tabla se presenta el valor que corresponde y la distribución de los porcentajes de cada copropietario asignado de acuerdo a la participación jurídica

En la tabla No. 3: se presenta el ingreso mensual de la copropiedad por $\$ 242,590$. con la estructura de los copropietarios con sus porcientos respectivos, así como el impuesto al valor agregado trasladado al contribuyente de forma proporcional de cada uno de los copropietarios y el total de IVA, por valor de \$ $38,814.39$, cabe mencionar que el representante común es responsable solidario de declarar el impuestos de todos los copropietarios.

\begin{tabular}{|l|r|r|}
\hline \multicolumn{1}{|c|}{ Concepto } & \multicolumn{1}{c|}{ Valor } & \multicolumn{1}{c|}{ IVA } \\
\hline Copropietario 1 & $\$ 16,132$. & $\$ 2,581.16$ \\
\hline Copropietario 2 & $\$ 107,710$. & $\$ 17,233.59$ \\
\hline Copropietario 3 & $\$ 40,391$. & $\$ 6,462.60$ \\
\hline Copropietario 4 & $\$ 46,092$ & $\$ 7,374.73$ \\
\hline Copropietario 5 & $\$ 16,132$ & $\$ 2,581.16$ \\
\hline Copropietario 6 & $\$ 16,132$. & $\$ 2,581.16$ \\
\hline Total & $\$ 242,590$ & $\$ 38,814.39$ \\
\hline
\end{tabular}

Tabla 3 En esta tabla se presenta la distribución de los ingresos mensuales del mes de enero 2019, de acuerdo a la proporción asignada, así como el impuesto al valor agregado según el ingreso de la proporción

En la tabla No. 4: se presenta la estructura mensual del mes de enero 2019, en la que contiene el ingreso de cada copropietarios, y el total del mismo $\$ 242,590$. así como la retención de Impuesto sobre la renta y el Impuesto al valor agregado respectivo, así se completa el cuadro completo que contiene el ingreso de cada copropietario mas el IVA, menos las retenciones de ISR e IVA que corresponde a cada copropietario, siendo el representante comun a enterar a la autoridad.

\begin{tabular}{|l|r|r|r|}
\hline \multicolumn{1}{|c}{ Concepto } & \multicolumn{1}{c|}{ Valor } & \multicolumn{1}{c|}{ Ret. ISR } & \multicolumn{1}{c|}{ Ret. IVA } \\
\hline $\begin{array}{l}\text { Copropietario } \\
\text { No. } 1\end{array}$ & $16,132$. & $1,613.22$ & $1,720.77$ \\
\hline $\begin{array}{l}\text { Copropietario } \\
\text { No. } 2\end{array}$ & $107,710$. & $10,770.99$ & $11,489.06$ \\
\hline $\begin{array}{l}\text { Copropietario } \\
\text { No.. 3 }\end{array}$ & $40,391$. & $4,039.12$ & $4,308.40$ \\
\hline $\begin{array}{l}\text { Copropietario } \\
\text { No. } 4\end{array}$ & 46,092 & $4,609.21$ & $4,916.49$ \\
\hline $\begin{array}{l}\text { Copropietario } \\
\text { No. 5 }\end{array}$ & 16,132 & $1,613.22$ & $1,720.77$ \\
\hline $\begin{array}{l}\text { Copropietario } \\
\text { No. 6 }\end{array}$ & $16,132$. & $1,613.22$ & $1,720.77$ \\
\hline Total & $\$ 242,590$ & $\$ 24,258.99$ & $\$ 25,876.26$ \\
\hline
\end{tabular}

Tabla 4 En esta tabla se presenta los ingresos del mes de enero 2019 así como la retención del IVA e ISR por obtener ingresos la persona física de la persona moral

Una vez que el representante común, percibe de forma efectiva el ingreso mensual de la copropiedad del mes de Enero de 2019, de acuerdo a la table No. 5: se realizará el cálculo del impuesto de ISR, y descontar la retención del impuesto sobre la renta, y se obtiene como resultado un cargo de $\$ 50,529$, tomar en cuenta que el representante común es el responsable de enterar o pagar los impuestos. 


\begin{tabular}{|l|l|r|}
\hline \multicolumn{2}{|c|}{ Concepto } & \multicolumn{1}{|c|}{ Valor } \\
\hline & valor & $\$ 242,590$ \\
\hline$(-)$ & Limite inferior & $\$ 97,183$ \\
\hline$=$ & Excedente de limite inferior & $\$ 145,407$ \\
\hline $\mathrm{X}$ & $\begin{array}{l}\% \text { del excedente de limite } \\
\text { inferior }\end{array}$ & $34 \%$ \\
\hline$=$ & Impuesto Marginal & $\$ 49,438$ \\
\hline+ & Cuota fija & $\$ 25,350$ \\
\hline$=$ & ISR Causado & $\$ 74,788$ \\
\hline$(-)$ & Retención de ISR & $\$ 24,259$ \\
\hline$=$ & ISR A Cargo & $\$ 50,529$ \\
\hline
\end{tabular}

Tabla 5 En esta tabla se presenta calculo mensual del mes de enero 2019, el cual el representante común es el obligado solidario a declarar por sus copropietarios ante la autoridad fiscal, y en forma interna se administran los impuestos de los copropietarios hasta concluir la anual

Se presenta el cálculo mensual de IVA del mes de enero 2019, de acuero a la tabla No. 6: el cual el representante común es el obligado solidario a declarar por sus copropietarios ante la autoridad fiscal, y en forma interna la distribución de impuestos que corresponde pagar a cada copropietario en el cual se obtiene como resultado IVA a cargo en Enero 2019 por $\$ 12,929$. Cabe mencionar que cuando se presente el mes de Febrero de 2019, los ingreos a declarar son los que corresponden al mes, es decir sin acumular los ingresos de meses anteriores como es el caso de otras actividades.

\begin{tabular}{|l|l|r|}
\hline \multicolumn{1}{|c|}{ Valor } & $\mathbf{\$ 2 4 2 , 5 9 0}$ \\
\hline+ & IVA Trasladado & $\$ 38,814$ \\
\hline$=$ & Subtotal 16\% & $\$ 281,404$ \\
\hline$(-)$ & IVA Retenido & $\$ 25,855$ \\
\hline$=$ & IVA Trasladado & $\$ 38,814$ \\
\hline$(-)$ & IVA Retenido & $\$ 25,885$ \\
\hline$=$ & IVA A Pagar & $\$ 12,929$ \\
\hline
\end{tabular}

Tabla 6 En esta tabla se presenta el cálculo mensual de IVA del mes de enero 2019, el cual el representante común es el obligado solidario a declarar por sus copropietarios ante la autoridad fiscal, y en forma interna la distribución de impuestos que corresponde a cada copropietario

Cálculo anual del copropietario No. 1, de acuerdo a la distribución de la tabla No. 2: el cual éste copropietario puede asignar en su declaración anual el $35 \%$ de deducción opcional para atenuar la carga tributaria y a la vez si está en sociedad conyugal puede distribuir su ingreso en 50\%. Asimismo, aplicar las deducciones personales y aun mas el estímulo de la educacion como son: la colegiatura, el efecto puede resultar saldo a favor de ISR.

\begin{tabular}{|l|l|r|}
\hline \multicolumn{2}{|c|}{ Valor } & $\mathbf{\$ 2 2 3 , 7 2 7}$ \\
\hline- & Limite inferior & $\$ 144,119$ \\
\hline$=$ & Excedente de limite inferior & $\$ 79,608$ \\
\hline$X$ & $\%$ del excedente de limite inferior & $21.36 \%$ \\
\hline$=$ & Impuesto Marginal & $\$ 17,004$ \\
\hline+ & Cuota fija & $\$ 15,262$ \\
\hline$=$ & ISR Causado & $\$ 32,266$ \\
\hline- & Retención de ISR & $\$ 22,372$ \\
\hline$=$ & ISR A Cargo & $\$ 9,894$ \\
\hline
\end{tabular}

Tabla 7 Cálculo anual del copropietario No. 1, de acuerdo a la distribución de la tabla No. 2, el cual este copropietario puede asignar en su declaración anual el $35 \%$ de deducción opcional para atenuar la carga tributaria y a la vez si esta cuenta con sociedad conyugal puede distribuir su ingreso en 50\%. Asimismo las deducciones personales y como efecto puede resultar saldo a favor de ISR

Cálculo anual del copropietario No. 3, de acuerdo a la distribución de la tabla No. 2: el cual este copropietario puede asignar en su declaración anual el $35 \%$ de deducción opcional para atenuar la carga tributaria y a la vez si está en sociedad conyugal puede distribuir su ingreso en 50\%. Asimismo las deducciones personales y aún más el estímulo de la educación como efecto puede resultar saldo a favor de ISR.

\begin{tabular}{|l|l|r|}
\hline \multicolumn{2}{|c|}{ Valor } & $\$ 560,159$ \\
\hline$(-)$ & Limite inferior & $\$ 458,132$ \\
\hline$=$ & Excedente de limite inferior & $\$ 102,027$ \\
\hline$X$ & \% del excedente de limite inferior & $30 \%$ \\
\hline$=$ & Impuesto Marginal & $\$ 30,608$ \\
\hline+ & Cuota fija & $\$ 85,953$ \\
\hline$=$ & ISR Causado & $\$ 116,561$ \\
\hline$(-)$ & Retención de ISR & $\$ 56,016$ \\
\hline$=$ & ISR A Cargo & $\$ 60,549$ \\
\hline
\end{tabular}

Tabla 8 Esta tabla muestra calculo anual del copropietario No 3., de acuerdo a la distribución de la tabla No. 2, el cual este copropietario puede asignar en su declaración anual el 35\% de deducción opcional para atenuar la carga tributaria y a la vez si esta cuenta con sociedad conyugal puede distribuir su ingreso en $50 \%$. Asimismo, las deducciones personales y como efecto puede resultar saldo a favor

Cálculo anual del copropietario No. 2, según la distribución de la tabla No. 2: el cual es el represententante común por contar con mayor porcentaje, este copropietario puede asignar en su declaración anual el 35\% de deducción opcional para atenuar la carga tributaria y a la vez si está en sociedad conyugal puede distribuir su ingreso en $50 \%$. 
Asimismo, las deducciones personales y aún más el estímulo de la educación como efecto puede resultar saldo a favor de ISR.

\begin{tabular}{|l|l|r|}
\hline \multicolumn{1}{|c|}{ Valor } & \multicolumn{1}{|c|}{$\mathbf{\$ 1 , 4 9 3 , 7 5 7}$} \\
\hline$(-)$ & Limite inferior & $\$ 1,166,200$ \\
\hline$=$ & Excedente de limite inferior & $\$ 327,557$ \\
\hline $\mathrm{X}$ & $\begin{array}{l}\text { \% del excedente de limite } \\
\text { inferior }\end{array}$ & $34 \%$ \\
\hline$=$ & Impuesto Marginal & $\$ 111,369$ \\
\hline+ & Cuota fija & $\$ 304,204$ \\
\hline$=$ & ISR Causado & $\$ 415,573$ \\
\hline$(-)$ & Retención de ISR & $\$ 149,376$ \\
\hline$=$ & ISR A Cargo & $\$ 266,197$ \\
\hline
\end{tabular}

Tabla 9 Esta tabla muestra calculo anual del copropietario No 2, que es el representante común de acuerdo a la tabla No. 2, el cual este copropietario puede asignar en su declaración anual el 35\% de deducción opcional para atenuar la carga tributaria y a la vez si esta en el regimen de sociedad conyugal puede distribuir su ingreso en 50\%, adicionalmente las deducciones personales, asi como las deducciones de educacion con las limitantes de la tabla No. 13

Cálculo anual del copropietario No. 4, de acuerdo a la distribución de la tabla No. 2: se sigue la misma simetría del cálculo anual de los tres copropietarios anteriores.

\begin{tabular}{|l|l|r|}
\hline \multicolumn{2}{|c|}{ Valor } & \multicolumn{1}{|c|}{$\mathbf{\$ 6 3 9 , 2 2 0}$} \\
\hline$(-)$ & Limite inferior & $\$ 158,132$ \\
\hline$=$ & Excedente de limite inferior & \\
\hline $\mathrm{X}$ & $\begin{array}{l}\text { \% del excedente de limite } \\
\text { inferior }\end{array}$ & $30 \%$ \\
\hline$=$ & Impuesto Marginal & $\$ 54,326$ \\
\hline+ & Cuota fija & $\$ 140,953$ \\
\hline$=$ & ISR Causado & $\$ 63,922$ \\
\hline$(-)$ & Retención de ISR & $\$ 76,357$ \\
\hline$=$ & ISR A Cargo & \\
\hline
\end{tabular}

Tabla 10 Esta tabla muestra calculo anual del copropietario No 4., de acuerdo a la distribución de la tabla No. 2, el cual este copropietario puede asignar en su declaración anual el 35\% de deducción opcional para atenuar la carga tributaria y a la vez si esta cuenta con sociedad conyugal puede distribuir su ingreso en $50 \%$. Asimismo las deducciones personales y como efecto puede resultar saldo a favor

De acuero a la tabla No. 11: se presenta los valores anuales que percibieron cada uno de los copropietarios incluyendo el representante común.

\section{Anual}

\begin{tabular}{|l|r|r|}
\hline \multicolumn{1}{|c|}{ Concepto } & \multicolumn{1}{c|}{ Valor } & \multicolumn{1}{c|}{$\%$} \\
\hline Copropietario 1 & $\$ 223,727.09$ & 6.65 \\
\hline Copropietario 2 & $\$ 1,493,756.81$ & 44.40 \\
\hline Copropietario 3 & $\$ 560,158.80$ & 16.65 \\
\hline Copropietario 4 & $\$ 639,220.26$ & 19.00 \\
\hline Copropietario 5 & $\$ 223,727.09$ & 6.65 \\
\hline Copropietario 6 & $\$ 223,727.09$ & 6.65 \\
\hline Total & $\$ 3,364,317.14$ & 100.00 \\
\hline
\end{tabular}

Tabla 11 Esta tabla presenta los valores anuales y el porcientos de la distribución de los copropietarios los cuales cada uno deberá declarar en forma individual en la declaración anual, como se presenta en la tabla

La tabla No. 12, se presenta cálculo del total de ingreso percibido para comparar el efecto del impuesto como si una sola persona percibiera el total del ingreso el cual pagaría \$ 1,051,564.00.

\begin{tabular}{|l|l|r|}
\hline \multicolumn{2}{|c|}{ Valor Anual } & $\mathbf{\$ 3 , 3 6 4 , 3 1 7}$ \\
\hline$(-)$ & Limite inferior & $\$ 1,166,200$ \\
\hline$=$ & Excedente de limite inferior & $\$ 2,198,117$ \\
\hline $\mathrm{X}$ & $\begin{array}{l}\% \text { del excedente de limite } \\
\text { inferior }\end{array}$ & $34 \%$ \\
\hline$=$ & Impuesto Marginal & $\$ 747,360$ \\
\hline+ & Cuota fija & $\$ 304,204$ \\
\hline$=$ & ISR Causado & $\$ 1,051,564$ \\
\hline$(-)$ & Retención de ISR & $\$ 443,156$ \\
\hline$=$ & ISR A Cargo & $\$ 336,431$ \\
\hline
\end{tabular}

Tabla 12 Esta tabla aparece la declaración anual como si se tratara de una sola persona para identificar que carece de beneficios por que una sola persona lo declararía el cien porciento y solo una persona deduce los beneficios

En esta tabla No. 13: se presenta el resúmen de impuestos de todos los copropietarios al considerar el porciento en su declaracion anual y entre todos pagaría \$ $769,211.00$, de impuestos, mientras que un solo contribuyente pagaría si ese fuese el caso según tabla No.12 por $\$ 1,051.564 .00$ esto tiene un efecto fiscal de $\$ 282,353.00$ de beneficio de impuestos al pagar en el régimen de copropiedad ya que la distribución de ingresos atenua la carga tributaria por ende es un beneficios que se demuestra con procedimientos y cálculos de impuestos según tablas expuestas. 


\begin{tabular}{|c|c|c|}
\hline ISR & No. Corpor. & Valor ISR \\
\hline$\$ 32,266$ & 3 & $\$ 96,798$ \\
\hline$\$ 1,493,757$ & 1 & $\$ 415,573$ \\
\hline$\$ 560,159$ & 1 & $\$ 116,561$ \\
\hline$\$ 639,220$ & 1 & $\$ 140,279$ \\
\hline \multicolumn{2}{|c|}{ Total ISR en copropiedad } & $\$ 769,211$ \\
\hline \multicolumn{2}{|c|}{ ISR de una persona } & $\$ 1,051,564$ \\
\hline \multicolumn{2}{|c|}{ Beneficio de ISR en copropiedad. } & $\$ 282,353$ \\
\hline
\end{tabular}

Tabla 13 Se presenta el resumen de impuestos de todos los copropietarios al considerar el porciento en su declaracion anual y entre todos pagaria $\$ 769,211.00$, de impuestos, mientras que un solo contribuyente pagaría si ese fuese el caso $\$ 1,051.564 .00$ esto tiene un efecto fiscal de $\$ 282,353.00$

\section{Estímulo Fiscal Decreto D.O.F. 2013.}

Los contribuyentes personas físicas como asalariados, régimen general de ley, servicios profesioales, pueden optar por aplicacar los estímulos que efrece el decreto de acuerdo a la tabla No. 14: y cumplir con los requisitos y las limitantes que ofrece.

Para hacer uso del beneficio se debe contar con el comprobante fiscal de pago con los requisitos fiscales, los cuales deben expedir las instituciones educativas privadas, los cuales se pueden deducir en la declaracion anual. Los pagos de colegiaturas son desde nivel preescolar hasta bachillerato o equivalente de acuerdo a las limitantes que se mencionan al calce (FEDERACION, 2018).

\begin{tabular}{|l|r|}
\hline \multicolumn{1}{|c|}{ Nivel educativo } & Limite deducción \\
\hline Preescolar & $\$ 14,200.00$ \\
\hline Primaria & $\$ 12,900.00$ \\
\hline Secundaria & $\$ 19,900.00$ \\
\hline Profesional técnico & $\$ 17,100.00$ \\
\hline Bachillerato técnico & $\$ 24,500.00$ \\
\hline Total & $\$ 88,600.00$ \\
\hline
\end{tabular}

Tabla 14 Estímulo fiscal por el pago de servicios educativos o colegiaturas, de acuerdo al decreto de beneficios fiscales para deducir en la declaración anual

En esta tabla No. 15: presenta caso práctico de la declaración anual del representante comun, con la parte proporcional, asimismo los beneficios de aplicar las disposiciones de ley, como es: a). la deducción opcional del $35 \%$, b). deducciones autorizadas, d). Estímulo fiscal de la educación menos retencion de ISR pagaría \$17,562.00, menos retención por haber percibido $\$ 1,493.757 .00$, adicional puede aplicar el régimen conyugal en el supuesto de aplicar.

\begin{tabular}{|c|c|c|}
\hline & $\begin{array}{l}\text { Ingreso acumulable por } \\
\text { arrendamiento de inmuebles }\end{array}$ & $\$ 1,493,757$. \\
\hline$(-)$ & Deducción opcional 35\% & $\$ 522,815$. \\
\hline$(-)$ & $\begin{array}{l}\text { Deducciones personales (gastos } \\
\text { médicos, por servicios } \\
\text { profesionales de psicología y } \\
\text { nutrición, funerarios, donativos, } \\
\text { intereses reales por créditos } \\
\text { hipotecarios, aportaciones } \\
\text { voluntarias a cuentas personales } \\
\text { de retiro, primas por seguros de } \\
\text { gastos médicos y transportación } \\
\text { escolar; no pueden exceder de } \\
\text { la cantidad que resulte menor } \\
\text { entre 5 veces el valor anual de } \\
\text { la UMA, o del 15\% del total de } \\
\text { los ingresos del contribuyente, } \\
\text { incluyen-do los exentos; en ese } \\
\text { límite no entran los gastos } \\
\text { médicos deri- vados de } \\
\text { incapacidades, los donativos ni } \\
\text { las aportaciones comple- } \\
\text { mentarias de retiro y } \\
\text { voluntarias) }\end{array}$ & $\$ 154,110$. \\
\hline$(=)$ & Base previa del impuesto & $\$ 816,832$. \\
\hline$(-)$ & $\begin{array}{l}\text { Estímulo fiscal por el pago de } \\
\text { ciertas colegiaturas }\end{array}$ & $\$ 88,600$. \\
\hline$(=)$ & Base del impuesto & $\$ 728,232$. \\
\hline$(=)$ & $\begin{array}{l}\text { Aplicación de la tarifa del } \\
\text { artículo } 152 \text { de la LISR }\end{array}$ & $\$ 166,938$. \\
\hline$(-)$ & $\begin{array}{l}10 \% \text { retenido por personas } \\
\text { morales durante el ejercicio }\end{array}$ & $\$ 149,376$. \\
\hline$(=)$ & ISR a cargo & $\$ 17,562$. \\
\hline$(-)$ & Pagos provisionales & \\
\hline$(=)$ & ISR a favor del ejercicio & $\$ 17,562$. \\
\hline
\end{tabular}

Tabla 15 Se presenta caso de la declaración anual del representante comun, con la parte proporcional, asimismo los beneficios de aplicar las disposiciones de ley como es la deduccion opcional del $35 \%$, deducciones personales, escolares o colegiaturas y regimen de sociedad conyugal

\section{Conclusiones}

Como estrategia es favorable por que es lícita, que el contribuyente planee la forma de tributacion que se le acomode con la condicionante que sea lícita. El régimen de copropiedad tiene muchos beneficios para los contribuyentes, y lo pueden aplican los estrategas fiscales por que el impuesto se atenúa, debido a que en lugar de ser un contribuyente el que declara la totalidad del ingreso, y las deducciones personales, así como el estímulo fiscal de las colegiaturas. Estos ingresos los puede declarar distribuido entre los integrantes del régimen de copropietarios y que estos a la vez cada uno en forma individual declarar los ingresos de acuerdo a la parte alícuota y a la vez aprovechar los beneficios como es: deducir el 35\% de deducción opcional, las deducciones personales, y el estimulo de colegiaturas. 
Asimismo si el copropietario esta obligado a declarar la parte alícuota éste a la vez, podrá aplicar el régimen de sociedad conyugal que corresponde al $50 \%$ de sus ingresos y a la vez este mismo podrá aplicar los beneficios mencionados y con este procedimiento el impuesto sobre la renta se va diluyendo sistemáticamente.

La carga administrativa disminuye es decir solamente un integrante de la copropiedad que es el representante común, esta obligado a declarar a la autoridad cada mes que son los pagos provisionales de impuesto sobre la renta y el impuesto al valor agregado, sin que el resto de los integrantes declaren, esto disminuye la carga administrativa, éstos solo están obligados a declarar de forma anual la parte que le corresponde.

\section{Se propone}

Que este régimen se difunda para que los contribuyentes puedan conocer los procedimientos y obligaciones para aplicarlo en forma inmediata, así poder obtener beneficios fiscales $\mathrm{y}$ disminuir la carga administrativa.

\section{Referencias}

CCDF. (2019). mexico,justia.com. (J. MEXICO, Producer) Retrieved 09 10, 2019, from Justia Mexico: mexico.justia.com/federales/codigos-civilfederal

Calvo, E., \& Montes, E. (2019). Ley de Impuesto sobre la Renta. LISR , 1.

CFF. (2019). COODIGO FISCAL DE LA FEDERACION. (THEMIS, Ed.) $C F F$.

LISR. (2019). Ley de Impuesto sobre la Renta Deduccion opcional 35\%. LISR , 1.

LIVA. (2019). Ley del Impuestos al valor agregado. (TEHMIS, Ed.) LEY DEL IVA , 1 .

CPEUM. (2019). Constitucion Poiitica de los Estados Unidos Mexicanos, nadie puede ser privado de su trabajo si es lícito. (www.diputados.gob.mx, Ed.) $C P E U$.
Cuadros, V. (1995). Derechos Reales. LIMA, DERECHOS REALES . Lima, LIMA, Peru.

FEDERACION, D. O. (2018, 12 26). ESTIMULO FISCAL 2013. 2013. MEXICO, MEXICO, MEXICO.

Jurídico, D. (1999). Copropiedad. Diccionario Jurídico . (I. Juridica, Ed., I. D. JURIDICAS, Trans., \& D. J. MEXICANO, Compiler) Mexico: Porrua.

RISR. (2019). Reglamento de impuesto sobre la RENTA. RISR , 1 .

TFJFA. (2019). Tribunal Fiscal Justicia Federal Administrativa. (T. Aislada, Ed.) TFJFA .

www.2.sat.gob.mxsitio. (2012, 08 01). www.sat.gob.mx. (DOF, Producer, \& SHCP) Retrieved from DOF: DOF www.2.sat.gob.mxsitio

Zúñiga, T. (2013). Los Juicios de inventario y participación judicial de bienes sustentados 